\title{
The Enlightenment of Management Teaching Method of Queensland University of Technology
}

\author{
Lina Wang1,2 \\ ${ }^{1}$ Economy \& Management School, Hainan Normal University, Haikou, China \\ ${ }^{2}$ Management School, Liaoning University of Technology, Jinzhou, China \\ Email: lina1976113@126.com
}

How to cite this paper: Wang, L.N. (2019) The Enlightenment of Management Teaching Method of Queensland University of Technology. Open Journal of Social Sciences, 7, 63-69.

https://doi.org/10.4236/jss.2019.74006

Received: March 15, 2019

Accepted: April 8, 2019

Published: April 11, 2019

Copyright () 2019 by author(s) and Scientific Research Publishing Inc. This work is licensed under the Creative Commons Attribution International License (CC BY 4.0).

http://creativecommons.org/licenses/by/4.0/

\section{c) (i) Open Access}

\begin{abstract}
After China's entry into WTO, the importance and urgency of developing and promoting bilingual teaching in colleges and universities is becoming increasingly prominent. In order to promote the reform of bilingual teaching in colleges and universities in Liaoning Province, this paper uses case law, taking the Advanced Higher Education Teaching practice of Queensland University of Technology as a case, to provide reference for English teaching in various colleges and universities in Liaoning province. Among them, the advanced teaching method of this school includes dozens of kinds, all from the teaching practice of colleges and universities, which has certain research value for the innovation of teaching methods in English instruction in colleges and universities in our province during the "Thirteen-Five" period. Practice has proved that the reform of teaching method is the key and is important to promote the reform of bilingual teaching in colleges and universities in Liaoning province.
\end{abstract}

\section{Keywords}

Queensland University of Technology, Management Pedagogy, Case Studies

\section{Introduction}

Bilingual teaching refers to a teaching mode in which a language other than Chinese (currently mainly refers to English) is directly applied to other courses outside the language curriculum, and the second language and knowledge of various subjects are obtained synchronously. "Some opinions issued by the Ministry of Education on strengthening undergraduate teaching in colleges and universities and improving teaching quality clearly put forward that it is necessary 
to actively promote the use of foreign languages such as English in colleges and universities, among which" undergraduate education should create conditions for the use of foreign languages such as English for the teaching of courses and specialties. "The opinion also specifically requires that' biotechnology, information technology and other specialties in the field of high and new technology, as well as the financial, legal and other specialties needed to adapt to China's accession to the WTO, should first step forward and strive to increase the proportion of foreign language teaching courses in these disciplines to $5 \%$ to $10 \%$ of the courses within three years." [1] [3] [4] [5]

It is understood that at present, there are more than 70 colleges and universities implementing bilingual teaching in China, including Peking University, Beijing Normal University, Tsinghua University, Zhejiang University, Xiamen University, Wuhan University, East China Normal University and other key universities. The Ministry of Education has set up a special "cooperation group on bilingual teaching in institutions of higher learning" to carry out bilingual teaching research, bilingual curriculum construction and bilingual teaching resource center construction throughout the country. The biggest challenge in implementing bilingual teaching is language. Professor Humin, School of Economics, Xiamen University, is currently trying to introduce bilingual instruction in the course of international economics. "Bilingual teaching is divided into three levels", she said. The first is the use of the original foreign language teaching materials to set up courses, followed by the use of English courseware in the classroom, student assignments and exams are also required to answer in English; the last level is full English teaching. Therefore, on the one hand, teaching teachers need to have excellent foreign language skills, especially the ability to express, and on the other hand, students' English proficiency should also pass, otherwise it will cause the class to understand and do not understand the results of the exam. In order to avoid the occurrence of the above situation, colleges and universities carrying out bilingual teaching have adopted the method of "grasping both hands", grasping the cultivation of teachers' English ability in one hand and grasping the improvement of students' English level in the other hand.

As the team leader of the "Cooperation group for bilingual teaching in institutions of higher learning", Zhejiang University has now opened 164 courses in the use of original foreign language teaching materials, bilingual or foreign languages for teaching. In order to improve teachers "foreign language teaching level, the school he studied expense more than 1000 teachers to study and train abroad every year, according to Zhang Cong, head of the school's Department of Education. In addition, in order to improve students" comprehensive use of foreign languages, the school starts with the improvement of basic foreign language teaching, on the one hand, to strengthen the teaching and training of English application in college foreign language teaching, on the other hand, to reduce the compulsory credits for college English, from the initial 16 credits to 12 credits, and to open more than 10 English, Germany, France and other foreign language audio-visual speaking aspects of the applied elective courses, in order 
to improve students' ability to apply foreign languages, in order to promote bilingual teaching to lay a good foundation [1].

Based on the "higher education teaching method abroad research and Repair project" of China National Study Abroad Fund Committee, this paper takes the dozens of team of lecturers, associate professors and professors from more than 10 universities in Liaoning province to the Department of Education of Queensland University of Technology in Australia for 3 months of English teaching training, experience, harvest, opinions and suggestions as a sample, for Liaoning Province in The Education Development Plan provides cases during the "Thirteen-Five" period, which provides reference for promoting the English teaching education system of colleges and universities in the new period of Liaoning Province, and provides teaching method system and empirical cases for promoting the reform and innovation of bilingual teaching in colleges and universities in Liaoning province. The main research contents of this paper include: teaching methods of the Department of Education of Queensland University of Technology, Australia; the role of teaching methods in English teaching in colleges and universities; and through the case of English teaching in Queensland University of Technology, this paper discusses the teaching methods of bilingual instruction adapted to the practice of colleges and universities in Liaoning.

\section{Problems in Bilingual Teaching Method in Colleges and Universities in Liaoning Province}

According to the reflection of college teachers in Liaoning province, combined with the research and practice of bilingual teaching theory in Liaoning province, [2], it is found that the following problems exist in the teaching method of bilingual teaching in colleges and universities in Liaoning province.

First of all, there is the idea of "assembly line production" in the teaching idea. During the Queensland University of Technology semester, a course was taught on the basis of university education. The course promotes student-centered rather than teacher-centered teaching, emphasizing student diversity. There are also group discussions in bilingual teaching in colleges and universities in our province, but they do not give students the principle of why to have a group discussion, and then the teaching concept is relatively old, only for a group of students, in fact, should focus on the individual differences of each student to carry out targeted teaching, Setting each student's individual learning goal may have better teaching effect.

Secondly, the teaching method is too single. For example, bilingual teaching in colleges and universities in Liaoning Province may be the main way for teachers to teach students, but for the management teaching method of Queensland University of Technology, it is found that if multiple teaching methods are introduced into the classroom, such as random groups, and then there is a group division of labor, which may better arouse students' enthusiasm for learning.

Thirdly, the advance design of the teaching link is insufficient. Bilingual 
teaching in colleges and universities in Liaoning province, teachers generally reflect the design of teaching links, teachers have a great amount of discretion, and then lead to some less responsible teachers on the pre-class teaching design links perfunctory. And the teachers at Queensland University of Technology have made a very deep impression on the serious attitude of the teaching design link. For example, Miss Michelle, before class, have to prepare a large number of discussion topics, activity plans and steps, and sometimes prepare sufficient card paper, color pens and other auxiliary tools, so that students can combine the object with a very clear purpose of discussion, can seriously follow the steps to participate in it; Classroom discussions are also more targeted, lively and interesting.

At the same time, in terms of teaching aids hardware and software, Liaoning Province, colleges and universities are uneven, student-oriented teaching concepts are not reflected. At Queensland University of Technology, there are hexagonal desks that are suitable for group students to discuss face to face; there are oversized touchable screens, both large and small, that can interact with students through the display; The library has different colors of seats on each floor, Red Orange is a quiet discussion area, Green Blue is a quiet learning area, The school is also equipped with a special discussion room.

\section{Queensland University of Technology Management Teaching Method Example}

There are more than 20 courses and teaching methods in the teaching of management pedagogy at Queensland University of Technology, which are briefly described below.

The relevant courses are: five aspects of higher education teaching; teaching and art; individual learning Plan; oral speech skills; micro-course teaching; Australian cultural academic research; strategies for the participation of major courses and small class students; curriculum development and evaluation procedures to ensure course quality; active academic programs; writing-self-feedback; language learning; reading and pronunciation, etc. In terms of management pedagogy, there are many teaching methods in each course, and there are many unique teaching methods suitable for multiple courses [3].

Active learning. Mainly includes active learning, effective questioning, as well as planning method. Requires active learning from the perspective of students and schools, respectively. Including learning Pyramid method, Frayer conceptual model strategy and so on.

Student participation. Mainly includes small class teaching, problem box, six hat model and so on. Each group has leaders, time managers, clerks and editors, six hats six colors, respectively, representing different personality characteristics, according to the color chosen to distinguish the type of manager, so as to determine the management method.

Culture. Including the conceptual model of culture; the introduction of local culture; and the study of the role of parents in the development of children. 
Micro classes. Including the evaluation of $-5 \mathrm{w} 1 \mathrm{~h}-\mathrm{who}$, what, location, why, purpose and how to proceed; some constructive suggestions were made; at the same time, the method of post-color thinking and learning pyramids focused on understanding the difference between deep learning and surface learning.

Oral presentation skills. Including dice methods; oral presentations; Body language; Steps for self-introduction; strategies to improve the level of speech; graphical methods; techniques for discussion; Structural observation of learning results; solo classification templates; Bloom taxonomy: The first layer is knowledge, then understanding, application, analysis, synthesis and evaluation, respectively.

English learning. Include the following steps: Brainstorming, then focusing on the point of view, taking into account the focus, then applying the strategy, and finally making plans and reviews.

The technique of engaging in scientific research in English. Including reflecting learning content; summary; topics, abstracts, keywords, quotes, literature review, theoretical methods, discoveries, discussions, summaries, literature reviews, etc.; report, relevance, reasoning, refactoring four parts: Introduction to the report paper, literature and questions related to the paper, reasoning and arguments related to the paper, Reconstruct the technical route and analysis method of the thesis.

Teaching five aspects. Emphasis is placed on differentiation, innovation, teaching of ideas, modeling and cultivation of thinking patterns.

How to write a summary. Positioning the research content of the paper (background, blank spots); research purposes; Writing methods, theories, analysis (main research content); Arguments and research necessity.

\section{The Enlightenment of Teaching Method Cases to Bilingual Teaching}

Queensland University of Technology management teaching method in addition to our display in English pronunciation and usage, as well as Australian culture, history and so on [6]. There are some enlightenment in the teaching methods of college teachers in colleges and universities, especially in Liaoning province, and even in bilingual teaching.

First, the deep and systematic understanding and grasp of the teaching process. For example, if it is a large class teaching, communicative teaching can be implemented, in the case of small classes, the form of discussion groups can be implemented, in the course of teaching, students should be checked at any time to understand the level of understanding, and make full use of classroom interaction and reflection teaching, to achieve the effect of raise one against.

Second, in the course construction should promote the research type rather than for the teaching and the teaching. Bilingual teachers should start from personal experience, research on domestic and foreign society, educational experience and so on, choose the appropriate teaching materials and curriculum system, the mountain stone can attack Jade, should be combined with foreign ad- 
vanced experience, should be used for local English teaching practice, can play the effect of twice the effort.

Third, the design of teaching links. First of all, teachers should create a relaxed and pleasant foreign language-learning environment for students. Although the hardest part of bilingual learning is language, let students relax from the atmosphere, have the desire to learn and self-confidence. Secondly, in the course of the design, to do more games, more students to participate, such as "Fish Tank theory", "Six Hats", "jigsaw puzzle" and so on, can let students play middle school, play in practice, to do fun.

Fourth, is the teaching mode, can make full use of interactive plus speech report form, can carry on the strict time management, such as let the student on a certain hot issue in English to preach, the time control within 5 minutes, then everyone carries on the question and answer discussion, does not adhere to the standard answer, only pursues the real sense listening, speaking and writing ability transfer. Promote a people-oriented, student-centered bilingual teaching model.

The fifth is to promote the use of microscopic teaching in the Queensland University of Technology in the assessment methodology. That is, most of the curriculum on the assessment of students should pay more attention to the learning process, that is, the usual results should account for a large proportion. In the process assessment, such as group case analysis, small paper writing, classroom discussion performance, etc. can be recorded in the usual results. At the same time, at the beginning of the teaching should be clearly provided to the students assessment content, requirements and evaluation criteria, students can be refined by the standard to prepare homework and assessment content, to achieve targeted. Six is to enrich the teaching methods. For example, "Dr. Edward's Six Hats", jigsaw puzzles, fish tank theory, jamming groups, thinking-pairing-shared TPS methods, Bloom taxonomy, etc. At the same time, let students have parallel thinking, comprehensive thinking rather than one-sided emphasis on local, but also to carry out enlightening teaching, so that students participate more, rather than teachers big deal, unidirectional teaching. In addition, students can also let go out, out of the classroom, more wind, research, so that the theory and practice better combination. What's more to learn is that ice-breaking exercises can be used to allow students to warm up quickly from strangers to familiarity; to designate English readings and videos, etc., to allow students to share translations and understandings in the classroom; and to learn the localization idioms of English-speaking countries.

\section{Conclusion}

This paper studies the management teaching method of Queensland University of Technology and its cases, especially with reference to the diversity and scientific nature of its management teaching methods, analyzes the problems existing in bilingual teaching in colleges and universities in Liaoning Province, and draws the Enlightenment to the bilingual teaching in colleges and universities in 
Liaoning province. In short, due to the different professional backgrounds of teachers, students have the ability and cultural differences; bilingual teaching reform and innovation should be more individual and targeted, in order to get better and faster development. The management teaching method case of Queensland University of Technology only plays a role, and the reform and development of bilingual teaching in the development planning of "Thirteen-Five" education in Liaoning Province requires more cases and the sharing and reference of successful experiences, and has a long way to go.

\section{Acknowledgements}

This work was financially supported by the Science and Technology project of Liaoning Science and Technology Bureau of 2017; project (20170540439); the project's name: The pollution controlling model system's construction based on middle-micro scale.

\section{Conflicts of Interest}

The author declares no conflicts of interest regarding the publication of this paper.

\section{References}

[1] Li, L. (2015) Full English Teaching for Teachers to Face New Challenges. 21st Century English Network (English Education Information, English Education Weekly Electronic Version)-11-10, Issue 18th. http://paper.i21st.cn/story/21407.html

[2] Liu, F. (2014) Research on the Problems and Countermeasures of Bilingual Teaching in Colleges and Universities in Liaoning Province in the Process of Internationalization. New Course.Early, No. 7, 97-97.

[3] Liu, H.S., et al. (2012) A Brief Talk on Bilingual Teaching of Microelectronics Course. Journal of Wuhan University (Science Edition), No. S2, 163-165.

[4] Yin, Y. (2014) Bilingual Teaching in Colleges and Universities: The Main Bridge Towards the Internationalization of Higher Education in China. Journal of Jiangxi Institute of Science and Technology, No. 3, 24-28.

[5] Sun, H.M., Wang, J.X., Wang, C.X., Li, X.Y. and Li, N.Y. (2012) The Combination of Open Students International Vision and the Cultivation of Innovative Ability and the Introduction of Bilingual Teaching Mode-Taking the Course of Flower Cultivation Technology in Shenyang Agricultural University as an Example. Journal of Shenyang Agricultural University (Social Science Edition), 14, 87-91.

[6] Li, X.M. and Yang, S. (2016) Characteristics and Enlightenment of Teaching Mode in the University of Exeter, Australia. Journal of Liaoning University of Technology (Social Science Edition), 18, 107-108. https://doi.org/10.1016/S1006-1266(08)60023-1 